Palumbo, M. D., D. C. Tozer, and K. A. Hobson. 2019. Origins of harvested Mallards from Lake St. Clair, Ontario: a stable isotope approach. Avian Conservation and Ecology 14(2):3. https://doi.org/10.5751/ACE-01389-140203

Copyright $(C) 2019$ by the author(s). Published here under license by the Resilience Alliance.

Research Paper

\title{
Origins of harvested Mallards from Lake St. Clair, Ontario: a stable isotope approach
}

\author{
Matthew D. Palumbo ${ }^{1,2,3}$, Douglas C. Tozer ${ }^{2}$ and Keith A. Hobson ${ }^{1,4}$ \\ ${ }^{1}$ Biology Department, Western University, London, Ontario, Canada, ${ }^{2}$ Long Point Waterfowl and Wetlands Research Program, Bird \\ Studies Canada, Port Rowan, Ontario, Canada, ${ }^{3}$ New York State Department of Environmental Conservation, Albany, New York, \\ USA, ${ }^{4}$ Environment and Climate Change Canada, Saskatoon, Saskatchewan, Canada
}

\begin{abstract}
Determining origins of waterfowl is important for establishing appropriate management and conservation strategies. In North America, much information is available from long-term mark-recapture programs involving banding on breeding or molting grounds. However, this approach is less able to identify origins of individuals across broad areas where banding effort is low. We used stable-hydrogen isotope analyses of feathers $\left(\delta^{2} \mathrm{H}_{\mathrm{f}}\right)$ from Mallards (Anas platyrhynchos) harvested during the 2014-2015 and 2015-2016 hunting seasons at Lake St. Clair (LSC), Ontario, Canada ( $n=237$ individuals). We created a feather isoscape and applied Bayesian assignment approaches to determine probability of origin. The proportion of hatch-year Mallards produced locally, i.e., at the same latitude as LSC, as opposed to farther north or south of LSC, ranged from $13.1 \%$ to $22.0 \%$ with almost no difference by sex. The proportion of after-hatch-year (AHY) birds that molted locally ranged from $3.5 \%$ to $11.7 \%$, with slightly fewer local AHY females compared with local AHY males. Nearly all birds that did not originate locally came from latitudes to the north of LSC, and only 2 from south of LSC. Whether this pattern is representative of locations in the Great Lakes beyond our study area is unknown but is of great relevance for harvest management. As such, we are expanding our study with plans to examine isotope-based origins of Mallards and other harvested waterfowl species at locations throughout the Great Lakes region. Because of its unique potential to fill knowledge gaps, we advocate the use of the stable isotope technique in the management of North American waterfowl and encourage more research in this area.
\end{abstract}

\section{Origines des colverts prélevés sur le Lac St. Clair, dans l'Ontario : approche par isotopes stables}

RÉSUMÉ. La détermination des origines des oiseaux aquatiques est importante pour établir des stratégies appropriées de gestion et de conservation. En Amérique du Nord, de nombreuses informations sont disponibles auprès des programmes de marquage-recapture à long terme qui comprennent le marquage des territoires de reproduction ou de mue. Toutefois, cette approche est moins efficace pour identifier les origines des individus dans de vastes régions où l'effort de marquage est peu important. Nous avons utilisé les analyses par isotopes d'hydrogène stable sur les plumes ( $22 \mathrm{Hf}$ ) de colverts (Anas platyrhynchos) prélevés au cours des saisons de chasse 2014-2015 et 2015-2016 sur le lac St. Clair (LSC), dans l'Ontario, au Canada ( $\mathrm{n}=237$ individus). Nous avons créé une isocarte des plumes et appliqué des modèles d'affectation bayesiens pour déterminer la probabilité d'origine. La proportion de colverts de l'année produits localement, c'est-à-dire à la même latitude que le LSC, par opposition aux individus provenant de régions plus au nord ou au sud du LSC, variait de $13,1 \%$ à $22,0 \%$, pratiquement sans différence entre les sexes. La proportion d'oiseaux après l'année d'éclosion qui avaient mué localement variait de 3,5\% à 11,7\% , les femelles étant légèrement moins nombreuses que les mâles après l'année d'éclosion. La grande majorité des oiseaux qui n'étaient pas originaires de la région provenaient de latitudes au nord du LSC et 2 seulement venaient du sud du LSC. On ignore si ce modèle est représentatif des sites de la région des Grands Lacs au-delà de notre région d'étude, mais cela est très pertinent pour la gestion des prélèvements. À ce titre, nous développons notre étude en élaborant des plans d'examen aux isotopes des origines des colverts et des autres espèces d'oiseaux aquatiques prélevés dans des sites répartis dans toute la région des Grands Lacs. Compte tenu de son potentiel unique pour combler les lacunes de connaissances, nous soutenons l'utilisation de la technique des isotopes stables dans la gestion des oiseaux aquatiques d'Amérique du Nord et encourageons d'autres recherches dans cette région.

Key Words: deuterium; harvest management; isoscapes; Mallard; origins; stable isotopes

\section{INTRODUCTION}

Understanding the strength of migratory connectivity of bird species between regions is important for guiding conservation and management (Hobson 1999, Studds and Marra 2005, Norris and Taylor 2006). Making such connections is particularly important for game bird species because harvest may include individuals from various regions of production under different management strategies. For waterfowl in North America, habitat conditions and productivity on the breeding grounds are linked to reported harvest within major migratory flyways in an adaptive decisionmaking process, which sets harvest regulations for each species each year (Nichols et al. 1995, Williams and Johnson 1995). As 
part of the process, three populations, based on their breeding ground affiliation, have been identified for Mallards (Anas platyrhynchos): western, midcontinent, and eastern(U.S. Fish and Wildlife Service 2017). Within the northeastern United States, the breeding population of Mallards has significantly declined since its peak in 1999 (Sauer et al. 2014). Harvested birds in the lower Great Lakes region could originate from the adjacent midcontinent or eastern breeding populations. Much of the existing demographic information for Mallards in North America has been from the midcontinent population, although knowledge gaps are increasingly being filled for the eastern population, including the lower Great Lakes region (Hoekman et al. 2004, 2006a, b, Coluccy et al. 2008, Messmer et al. 2015). Migratory connectivity of the eastern population of Mallards in the Great Lakes region, however, has received little attention. Therefore, information linking harvested birds to their breeding population of origin is important for harvest management.

Harvested waterfowl are commonly linked to breeding populations through hunter reports of leg bands applied during the summer prior to the hunting season, i.e., direct recoveries. These data suggest that Mallards harvested in the Great Lakes states of Wisconsin, Michigan, Illinois, Indiana, and Ohio are predominantly separate from the larger midcontinent population and that the majority of harvest originates from locally breeding Mallards (Anderson and Henry 1972, Munro and Kimball 1982, Zuwerink 2001). Band recovery data are difficult to obtain for large numbers of individuals across large spatial scales (Austin et al. 2000). Band recoveries may also be biased toward the geographic region of sampling (Hobson 2008). For example, the natal origins of Mallards harvested during the hunting season are uncertain unless the recovered birds are banded prior to fledging (Szymanski et al. 2007). The use of naturally occurring stable isotope ratios provides a means to help overcome these difficulties and gain greater understanding of natal as well as molt origins of harvested waterfowl (Caizergues et al. 2016, Asante et al. 2017). Origins of harvested birds can be estimated from stable hydrogen isotopes $\left({ }^{2} \mathrm{H} /{ }^{1} \mathrm{H}\right.$ measured as $\left.\delta^{2} \mathrm{H}\right)$ in metabolically inert tissues such as fully grown feathers because these isotopes change predictably in food webs across the continent. Newly hatched waterfowl grow their flight feathers at natal locations while adults experience simultaneous annual wing molt leaving them flightless during regrowth (Baldassarre and Bolen 2006). Attributable in part to lack of mobility, Mallards sometimes undertake a molt migration away from their breeding marshes that varies in distance among individuals and by sex to locations that are more favorable in terms of predation pressure and available food resources during the flightless period (Baldassarre 2014). Thus, stable hydrogen isotopes in feathers $\left(\delta^{2} \mathrm{H}_{\mathrm{f}}\right)$ of harvested birds potentially provide information on origin as a function of age, sex, and other factors. Origins of several waterfowl populations in North America, including different age and sex cohorts, have been described using these methods (Szymanski et al. 2007, Yerkes et al. 2008, Hobson et al. 2009, Ashley et al. 2010, Asante et al. 2017). In the context of the lower Great Lakes region, $\delta^{2} \mathrm{H}_{\mathrm{f}}$ measurements provide a useful means for determining latitudinal origins of harvested Mallards across a much broader geographic extent, and with much larger sample sizes than banding recoveries or other current tools allow.
Lake St. Clair (LSC) and the surrounding wetlands is one of the most important waterfowl staging areas in the Great Lakes, providing approximately 4 million to 7 million duck use days, i.e., carrying capacity estimate of ducks scaled to 1 day, with peak abundance of 123,000-150,000 dabbling ducks during autumn migration (Dennis et al. 1984; D. R. Luukkonen, Michigan Department of Natural Resources, personal communication). The LSC region has experienced substantial wetland loss and is influenced by several environmental stressors, e.g., increased abundance of invasive species and intensive agricultural practices (Weaver, Petrie, Richman, et al., unpublished manuscript). Many of the remaining wetland complexes on the Canadian shore of the lake are intensively managed to attract and sustain waterfowl populations during autumn and winter for the purposes of harvesting ducks (Bookhout et al. 1989; Weaver, Petrie, Richman, et al., unpublished manuscript). Coluccy et al. (2008) used data from studies conducted in western Great Lakes states and determined that nonbreeding season survival of adult female Mallards influences growth of the Great Lakes Mallard population, and they recommended harvest management as a strategy for conservation of the population. For Mallards, some states in the Great Lakes region restrict daily bag limits and specifically protect females from harvest relative to Ontario because it is suspected that a substantial portion of these ducks originate locally and they aim to protect their breeding population (Singer 2014). As an important staging area, it is assumed that the Mallards that use LSC are a mix of birds that hatched and molted within the Great Lakes region and migrants from farther north, although the composition of the mix remains uncertain. Gaining better knowledge of the composition of stocks in the harvest will assist in assessing the sustainability of harvest for those stocks and the utility of current harvest regulations in this region of Ontario.

Our goal was to refine our understanding of the origins of hunterharvested Mallards from LSC, using stable isotope methods. To meet our goal, we estimated natal and molt origins of male and female Mallards harvested on the Canadian shore of LSC during the 2014-2015 and 2015-2016 hunting seasons. Furthermore, we wanted to determine if there were temporal differences related to the origin for early harvested compared to late-harvested individuals. We hypothesized that there would be latitudinal differences in natal and molt origins of individuals harvested at different times throughout the hunting season, as birds migrate through the staging area during autumn and winter. Therefore, we predicted that birds harvested early in the hunting season would originate from lower latitudes, whereas individuals harvested later in the hunting season would be from farther north. As harvest management has been suggested for the Great Lakes population of Mallards, our study provides unique information on the origin and migratory connectivity of a portion of this population in the LSC region.

\section{METHODS}

\section{Study area}

As part of the Great Lakes system, LSC is a relatively shallow (mean depth of $3 \mathrm{~m}$ ) connector lake between Lake Huron and Lake Erie. The lake is intersected by the international border between Michigan, USA, and Ontario, Canada. We sampled harvested 
waterfowl from private properties and boat launches that allowed access to public hunting areas of the Canadian side of the lake (Fig. 1). The Canadian side of the lakeshore is primarily cultivated for corn, wheat, and vegetables including beans, beets, celery, peas, onions, peppers, carrots, and tomatoes (Weaver, Petrie, Richman, et al., unpublished manuscript). Within this landscape, there are sparse native wetland vegetation communities and several impounded wetlands. Along the eastern shore of LSC, there are approximately 2305 ha of wetlands composed of $19 \%$ aquatic beds, 38\% cattail (Typha spp.), 33\% Phragmites spp., 9\% shrub wetland, $1 \%$ forested wetland, and $1 \%$ other (Weaver, Petrie, Richman, et al., unpublished manuscript).

Fig. 1. Eastern shore of Lake St. Clair, Ontario (black oval). All of the wings from harvested Mallards (Anas platyrhynchos) for this study were obtained within this area.

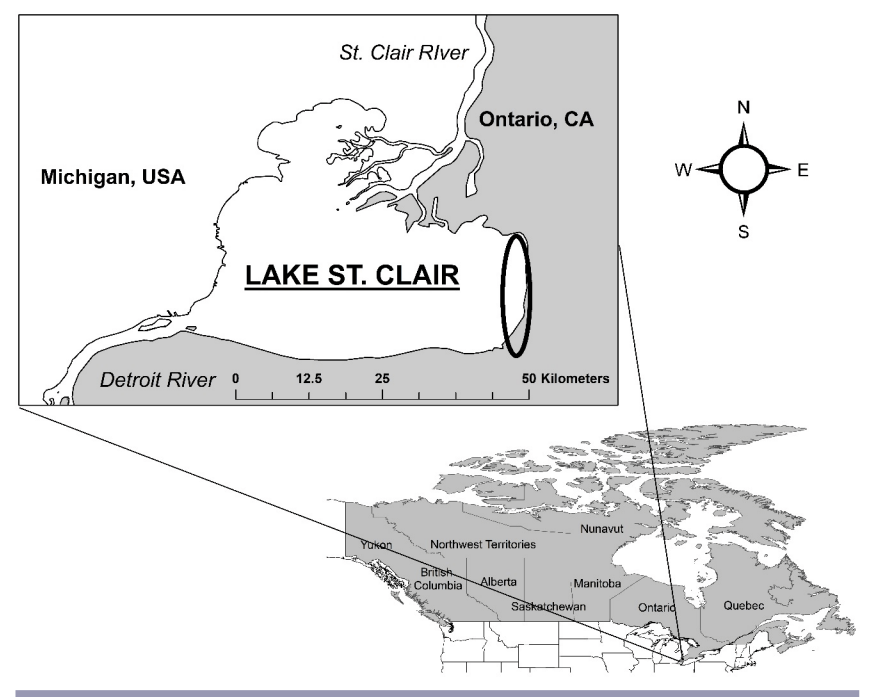

\section{Sample collection, identification, and preparation}

The 2014-2015 and 2015-2016 Ontario southern zone open hunting seasons were from 27 September 2014 to 10 January 2015 and from 26 September 2015 to 9 January 2016 (each 106 d in duration). We selected individuals for analysis from 677 hunterharvested Mallards from the 2014-2015 season and 1239 Mallards from the 2015-2016 season (Canadian Wildlife Service permit: SA 0261). To ensure adequate sample sizes to investigate temporal, sex, and age differences related to origin, we randomly stratified wings selected for analysis equally between the early (September through October) and late (December through January) part of each hunting season, between each sex, and between after-hatch-year (AHY) and hatch-year (HY), such that 30 wings were selected for analysis from within each of 2 earlylate $\times 2$ sex $\times 2$ age $=8$ combinations $(n=240$ individuals $)$. We determined sex and age of each individual based on wing characteristics (Carney 1992). We removed the most distal primary feather from each wing for analysis.

\section{Stable hydrogen isotope analysis}

Feather samples were analyzed for $\delta^{2} \mathrm{H}$ at the National Hydrology Research Center of Environment Canada in Saskatoon, Saskatchewan. After washing in a 2:1 chloroform:methanol solution, feather samples were loaded into silver capsules and placed with standards into a zero blank carousel under helium flow. Pyrolysis combustion on glassy carbon was at $1350^{\circ} \mathrm{C}$ in a Hekatek furnace, and gases were separated using a Eurovector Elemental Analyzer (Milan, Italy) interfaced with an Elementar Isoprime (Isoprime, Manchester, UK) Continuous Flow Isotope Mass Spectrometer. Analysis of $\delta^{2} \mathrm{H}$ was conducted using the comparative equilibration method of Wassenaar and Hobson (2003) with 3 calibrated keratin reference materials (CBS, $\delta^{2} \mathrm{H}$ $=-197 \%$; KHS, $\delta^{2} \mathrm{H}=-54.1 \%$; SPK, $\delta^{2} \mathrm{H}=-121.6 \%$ ) corrected for linear instrumental drift. Based on within-run analyses $(n=5$ each) of the keratin standards, measurement error was approximately $\pm 2 \%$ for hydrogen isotopes in feather $\left(\delta^{2} \mathrm{H}_{\mathrm{f}}\right)$. All $\delta^{2} \mathrm{H}$ values are reported relative to the Vienna Standard Mean Ocean Water-Standard Light Antarctic Precipitation scale.

\section{Assignment to origin}

Previous studies have used estimates of the amount-weighted mean annual or growing season precipitation $\delta^{2} \mathrm{H}\left(\delta^{2} \mathrm{H}_{\mathrm{p}}\right)$ to estimate expected $\delta^{2} \mathrm{H}_{\mathrm{f}}$ at a given location using an appropriate calibration algorithm (Bowen et al. 2005, Hobson 2008). Habitats supporting waterfowl are likely best approximated by the mean annual $\delta^{2} \mathrm{H}_{\mathrm{p}}$ or by waters directly driving the hydrogen budget of the wetlands (Asante et al. 2017). LSC receives waters directly from Lake Huron, and LSC lake water consistently falls between $-49 \%$ and $-52 \%$ (Theodory 1999; L. Wassenaar, International Atomic Energy Agency, personal communication). The mean annual precipitation $\delta^{2} \mathrm{H}_{\mathrm{p}}$ is predicted to be slightly more negative at -59\% (Bowen and Revenaugh 2003; http://waterisotopes.org). We assumed waterfowl growing feathers at LSC were exposed to a food web driven primarily by LSC waters (i.e., $-49 \%$ o to $-52 \%$ ), but it is also possible that marshes in the area were influenced by mean annual precipitation.

Prior to assigning birds to their natal or molt origins, we first assigned birds as locals, i.e., birds originating from the same latitude as LSC, versus immigrants using likelihood-based assignments. We calculated the expected feather value for birds molting on LSC $\left(\delta^{2} \mathrm{H}_{\mathrm{fd}}\right)$ by applying a rescaling function derived by regressing $\delta^{2} \mathrm{H}_{\mathrm{f}}$ of known-origin Lesser Scaup (Aythya affinis) against $\delta^{2} \mathrm{H}_{\mathrm{p}}$ (Clark et al. 2006, 2009). This exercise provided the parameters for the equation $\delta^{2} \mathrm{H}_{\mathrm{f}}=-31.6+0.93 \times \delta^{2} \mathrm{H}_{\mathrm{p}}$, which we then used to rescale our LSC water values $(-49 \%$ o to $-52 \%$ ), resulting in a predicted mean $\delta^{2} \mathrm{H}_{\mathrm{fd}}$ ranging between $-77 \%$ and $-80 \%$. We compared the observed $\delta^{2} \mathrm{H}_{\mathrm{f}}$ for unknown-origin birds against the predicted mean $\delta^{2} \mathrm{H}_{\mathrm{f}}$ using a normal probability density function to assess the likelihood that the unknown origin sample had grown its feather on LSC given expected variation in $\delta^{2} \mathrm{H}_{\mathrm{f}}$ between individuals growing their feathers at the same location. We estimated expected variation using the distribution of residuals $(\mathrm{SD}=12.8 \%$ ) from the Clark et al. $(2006,2009)$ rescaling function. If $\delta^{2} \mathrm{H}_{\mathrm{f}}$ fell within $\pm 12.8 \%$ around the expected $\delta^{2} \mathrm{H}_{\mathrm{f}}$ for LSC $\left(\delta^{2} \mathrm{H}_{\mathrm{fd}}\right)$, they were classified as local birds based on a 2:1 odds ratio. We examined the sensitivity of our analyses by repeating this approach using a $3: 1$ odds ratio corresponding to $\delta^{2} \mathrm{H}_{\mathrm{f}}$ falling within $\pm 14.1 \%$ (i.e., $1.15 \times 12.8$ ) 
of $\delta^{2} \mathrm{H}_{\mathrm{fd}}$ (Chabot et al. 2012, Van Wilgenburg et al. 2012, Wunder 2012). Birds not falling within the expected range for LSC were classified as northern birds if $\delta^{2} \mathrm{H}_{\mathrm{f}}$ was less than $\delta^{2} \mathrm{H}_{\mathrm{fd}}-12.8 \%$ o (at 2:1 odds), or southern birds if $\delta^{2} \mathrm{H}_{\mathrm{f}}$ was greater than $\delta^{2} \mathrm{H}_{\mathrm{fd}}+$ $12.8 \%$.

To further elucidate the origins of immigrant birds, we used likelihood-based assignment algorithms to conduct spatially explicit assignments to origin (Hobson et al. 2009, Wunder 2010, Van Wilgenburg and Hobson 2011). We created a map (hereafter isoscape) of predicted $\delta^{2} \mathrm{H}$ in feathers $\left(\delta^{2} \mathrm{H}_{\mathrm{f}}\right)$ by applying the rescaling function of Clark et al. $(2006,2009)$ to rescale the precipitation amount-weighted growing season $\delta^{2} \mathrm{H}$ in the precipitation map $\left(\delta^{2} \mathrm{H}_{\mathrm{p}}\right)$ of Bowen et al. (2005) into equivalent feather values. We used a spatial mask operation to limit the isoscape to only those areas of the continent falling exclusively within the species' breeding range based on a digital breeding range map (Ridgely et al. 2007). We also considered Mallards to be originating only from either the Central, Mississippi, or Atlantic flyways (Weaver, Petrie, Richman, et al., unpublished manuscript). In addition to the aforementioned isoscape, we also used a Bayesian prior approach to account for the probability of birds being harvested at LSC originating in each of the three flyways based on band recovery data (see next paragraph for details), and we compared the assignments based on this result to assignments based on an isoscape unconstrained by flyway (Hobson et al. 2009, Asante et al. 2017).

To determine the probability of a bird harvested at LSC as being from the Central, Mississippi, or Atlantic flyways, we summarized available (through January 2017) band recovery data from the U. S. Geological Survey Gamebirds database (U.S. Geological Survey 2017). We queried the database for all reported Mallard band recoveries in Ontario and displayed the location of each recovery in a geographic information system (ArcGIS 10.5.1, Environmental Systems Research Institute Inc., Redlands, California, USA). We then selected recoveries associated with the eastern shore of LSC. This area was approximately 45,000 ha and resulted in 4002 reported Mallard band recoveries (Appendix 1). We then replotted each recovery based on its associated banding coordinates to assign a flyway for each recovery. This process resulted in 615 recoveries from the Atlantic flyway, 68 from the Central flyway, and 3317 from the Mississippi flyway. Band recovery data provided the probability of any individual coming from a respective flyway. We applied that derivation of probability before the threshold decision-making step.

Following isoscape creation, we estimated the likelihood that individual cells, i.e., pixels, within the isoscape represented a potential origin for a given sample by comparing the observed $\delta^{2} \mathrm{H}_{\mathrm{f}}$ against the isoscape-predicted $\delta^{2} \mathrm{H}_{\mathrm{f}}$ using a normal probability density function (Hobson et al. 2009). Following Hobson et al. (2009), we then applied Bayes's theorem to assess the posterior probability that an individual pixel within the isoscape was the putative origin of a given sample. After normalizing the probabilities to sum to 1 , we assigned individuals to likely origins within the isoscape by selecting the raster cells that were consistent with the upper $67 \%$ of estimated probabilities of origin for each individual and coded those as 1 and all others as 0 . In addition, we examined sensitivity to the choice of odds ratio by repeating the assignments by selecting the upper $75 \%$ of estimated "probabilities of origin" for each individual and coding those as 1 , and all others as 0 consistent with 3:1 odds. We subsequently summed the results of the assignments over all individuals by addition of the surfaces (Hobson et al. 2009, Van Wilgenburg and Hobson 2011). We also contrasted these results with those using a simple cumulative probability approach, i.e., normalizing all pixel probabilities to add to 1 , as our data were not bimodal (Wunder 2010). Given that depicted origins were similar among these various approaches, we report all depictions of origins with 2:1 odds.

\section{Temporal, age, and sex comparisons}

We used linear regression models and an information theoretic approach with second-order Akaike's information criterion for small sample sizes (AICc) to select a most parsimonious model or group of models from a set of candidate models (Burnham and Anderson 2002). We used the best model or group of models and associated model predictions to make inferences for $\delta^{2} \mathrm{H}_{\mathrm{f}}$ as a function of day of hunting season (e.g., $1=$ opening day through to $106=$ closing day), age, and sex. Where faced with model selection uncertainty, we used model averaging and based inferences on all of the models that included each variable (Burnham and Anderson 2002). First, we compared a model with hunting season compared with an intercept-only model to determine if $\delta^{2} \mathrm{H}_{\mathrm{f}}$ differed in the 2014-2015 hunting season compared with the 2015-2016 hunting season. We then developed separate model sets for each year to explore the influence of all single-variable (3 models) and all 2-variable additive combinations ( 3 models) of day of hunting season, age, and sex, along with an intercept-only and global model, which included all of the variables, a total of 8 models in each model set for each hunting season. We did not consider interactions among variables. We evaluated the importance of variables in the best model or group of models by examining confidence limits around parameter estimates; in cases with model selection uncertainty, variables with $85 \%$ confidence limits that did not contain zero were considered important (Arnold 2010). We also examined relative importance values to help evaluate importance. All linear regression models were implemented in $\mathrm{R}$ version 3.4.3 ( $\mathrm{R}$ Core Team 2018). We standardized ( $z$-transformed) all variables prior to analysis to facilitate comparison of coefficients. We report $95 \%$ confidence limits for parameter estimates, as well as $85 \%$ confidence limits where noted to help determine importance of variables in light of model selection uncertainty (Arnold 2010).

\section{RESULTS}

We aimed to select feathers from 240 individual Mallards for analysis, equally distributed among early and late parts of each hunting season, sexes, and ages, although feather samples were lost for 3 individuals, so our final $n=237$ individuals, with nearly equal distribution among the desired categories (Table 1, Appendix 2). A model containing hunting season received compelling support (year effect $=-2.9[-5.5,-0.4]$, Akaike weight $[w]=0.87)$ compared with an intercept-only model $(\triangle \mathrm{AICc}=3.2$, $w=0.13$ ). As such, $\delta^{2} \mathrm{H}_{\mathrm{f}}$ was higher (more southerly) during the 2014-2015 hunting season (-107.6 [-112.1, -103.1]) than during the 2015-2016 hunting season (-114.0 [-117.0, -110.9]). Because of this difference, we analyzed each hunting season separately. 
There was model selection uncertainty within each model set for each hunting season (Table 2), so we examined model-averaged estimates and associated $85 \%$ confidence limits, as well as relative importance values, to identify important variables for each hunting season (Table 3). Day of hunting season and sex, but not age, were important for explaining $\delta^{2} \mathrm{H}_{\mathrm{f}}$ during the 2014-2015 hunting season, whereas day of hunting season and age, but not sex, were important for explaining $\delta^{2} \mathrm{H}_{\mathrm{f}}$ during the 2015-2016 hunting season (Table 3). During the 2014-2015 hunting season, likely origins based on $\delta^{2} \mathrm{H}_{\mathrm{f}}$ got more northerly as the day of hunting season got later, and males had more southerly origins than females (Fig. 2). During the 2015-2016 hunting season, origins got more northerly as day of hunting season progressed, and HY had more southerly origins than AHY (Fig. 2).

Table 1. Estimates of the number of local Mallards (Anas platyrhynchos) derived from stable isotope assignments using 2:1 and 3:1 odds, as well as the maximum and minimum estimates of local water $\delta^{2} \mathrm{H}$.

\begin{tabular}{lcrrrrr}
\hline \hline & & \multicolumn{2}{c}{$2: 1$ Odds } & & \multicolumn{2}{c}{$3: 1$ Odds } \\
\cline { 3 - 4 } Sample & $n$ & \multicolumn{1}{c}{$\begin{array}{c}\text { Minimum } \\
(\%)\end{array}$} & $\begin{array}{c}\text { Maximum } \\
\text { (\%) }\end{array}$ & $\begin{array}{c}\text { Minimum } \\
(\%)\end{array}$ & $\begin{array}{c}\text { Maximum } \\
(\%)\end{array}$ \\
\hline AHY female & 57 & $2(3.5)$ & $3(5.3)$ & $2(3.5)$ & $6(10.5)$ \\
AHY male & 60 & $7(11.7)$ & $7(11.7)$ & $8(13.3)$ & $8(13.3)$ \\
HY female & 61 & $8(13.1)$ & $11(18.0)$ & $11(18.0)$ & $13(21.3)$ \\
HY male & 59 & $8(13.5)$ & $13(22.0)$ & $13(22.0)$ & $13(22.0)$ \\
Total & 237 & $25(10.6)$ & $34(14.4)$ & $34(14.4)$ & $40(16.9)$ \\
& & & & & & \\
\hline
\end{tabular}

We identified local versus immigrant individuals using expected $\delta^{2} \mathrm{H}_{\mathrm{f}}$ of birds produced in the LSC region and assignment based on both a 2:1 odds ratio and a more conservative $3: 1$ odds ratio. We also considered a range of possible local water $\delta^{2} \mathrm{H}$. This exercise provided a range of estimates of the number of local birds corresponding to a low estimate of the number of locals (2:1 odds ratio and most positive local water $\left.\delta^{2} \mathrm{H}\right)$ to a high estimate $(3: 1$ odds ratio and most negative local water $\delta^{2} \mathrm{H}$ ). By any criteria, only 2 individuals were classified as being from south of our study area (i.e., with more positive $\delta^{2} \mathrm{H}_{\mathrm{f}}$ ), and all other birds classified as immigrants were from the north (i.e., with more negative $\delta^{2} \mathrm{H}_{\mathrm{f}}$; Fig. 3). Using the 2:1 odds ratio, the percent of HY Mallards produced locally ranged from $13.1 \%$ to $22 \%$, with almost no difference in the number of local HY birds by sex (Table 1). Using the same odds ratio, the percent of adults that molted locally versus outside our area ranged from $3.5 \%$ to $11.7 \%$, with slightly fewer local AHY females compared with males (Table 1).

The majority of harvested Mallards at LSC had $\delta^{2} \mathrm{H}_{\mathrm{f}}$, consistent with molt or natal origins in the boreal wetlands of northwestern Ontario, but also possibly including southeastern Manitoba and Labrador (Fig. 4A). Based on band recovery data, we determined that the probability of origin of a Mallard immigrating to LSC was greatest from the Mississippi flyway (0.829), followed by the Atlantic flyway (0.154), and the Central flyway (0.017). When we applied the Bayesian prior probabilities to our assignment, the potential origins were constrained to primarily the Mississippi flyway (Fig. 4B).
Table 2. Model selection results for 8 candidate models explaining stable hydrogen isotopes $\left({ }^{2} \mathrm{H} /{ }^{1} \mathrm{H}\right)$ in Mallard (Anas platyrhynchos) wing feathers $\left(\delta^{2} \mathrm{H}_{\mathrm{f}}\right)$ harvested along the eastern shore of Lake St. Clair, Ontario, during the 2014-2015 hunting season and the 2015-2016 hunting season. AICc, Akaike information criterion; $K$, number of parameters; LL, log likelihood; $w$, Akaike weight.

\begin{tabular}{lccccc}
\hline \hline Model & $K$ & LL & AICc & $\Delta$ AICc & $w$ \\
\hline 2014-2015 Hunting season & & & & & \\
Day of season + sex & 4 & -316.1 & 640.7 & 0.00 & 0.48 \\
Day of season & 3 & -318.0 & 642.4 & 1.66 & 0.21 \\
Day of season + age + sex & 5 & -315.9 & 642.6 & 1.87 & 0.19 \\
Day of season + age & 4 & -317.9 & 644.5 & 3.74 & 0.07 \\
Sex & 3 & -320.4 & 647.1 & 6.32 & 0.02 \\
Age + sex & 4 & -319.9 & 648.5 & 7.73 & 0.01 \\
Intercept only & 2 & -322.2 & 648.6 & 7.81 & 0.01 \\
Age & 3 & -322.0 & 650.3 & 9.56 & 0.00 \\
& & & & & \\
2015-2016 Hunting season & & & & & \\
Day of season + age & 4 & -708.6 & 1425.4 & 0.00 & 0.45 \\
Day of season + age + sex & 5 & -708.5 & 1427.4 & 1.99 & 0.17 \\
Age & 3 & -710.7 & 1427.5 & 2.07 & 0.16 \\
Day of season & 3 & -711.2 & 1428.5 & 3.13 & 0.09 \\
Age + sex & 4 & -710.6 & 1429.4 & 4.04 & 0.06 \\
Day of season + sex & 4 & -711.1 & 1430.4 & 5.04 & 0.04 \\
Intercept only & 2 & -713.6 & 1431.2 & 5.80 & 0.02 \\
Sex & 3 & -713.5 & 1433.1 & 7.69 & 0.01 \\
\hline & & & & &
\end{tabular}

Fig. 2. Stable hydrogen isotopes $\left({ }^{2} \mathrm{H} /{ }^{1} \mathrm{H}\right)$ in Mallard (Anas platyrhynchos) wing feathers $\left(\delta^{2} \mathrm{H}_{\mathrm{f}}, n=237\right.$ individuals) harvested along the eastern shore of Lake St. Clair, Ontario, as a function of hunting season, sex, age, and day of hunting season. Shown are model-averaged estimates (solid blue dots and blue lines) and associated 95\% confidence intervals (black lines), along with raw data (open gray dots).
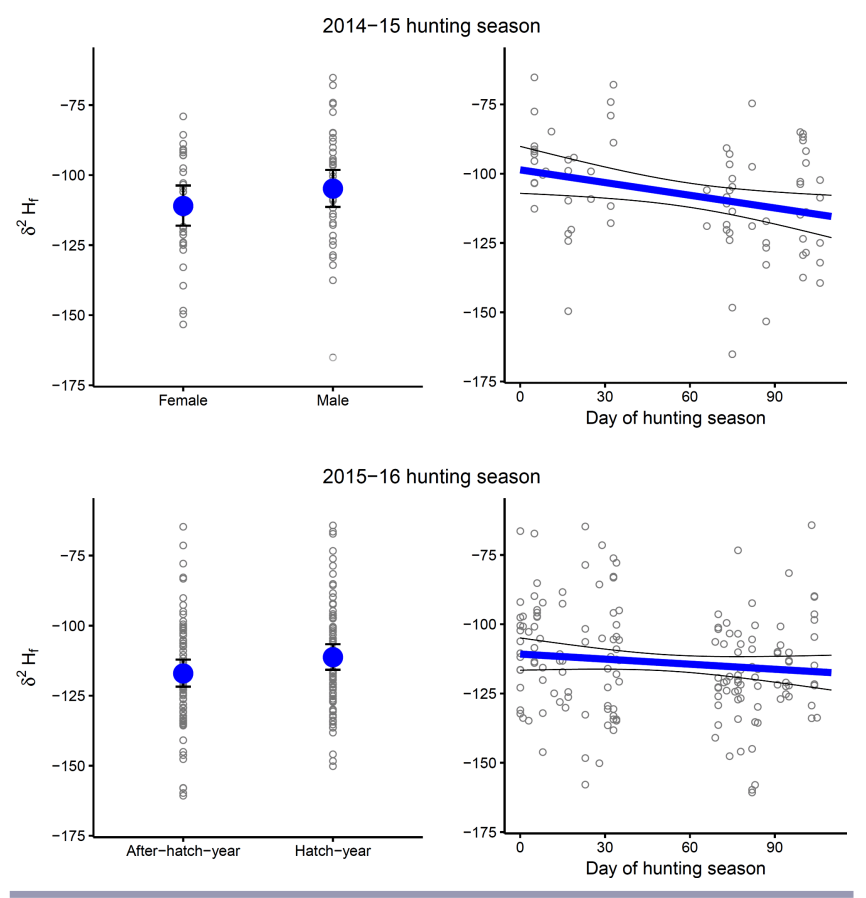
Table 3. Model-averaged parameter estimates (Est.), associated confidence limits (CLs; 85\% and 95\%), and relative importance values calculated as cumulative Akaike weights $(\Sigma w)$ for variables used to model stable hydrogen isotopes $\left({ }^{2} \mathrm{H} /{ }^{1} \mathrm{H}\right)$ in $\mathrm{Mallard}($ Anas platyrhynchos) wing feathers $\left(\delta^{2} \mathrm{H}_{\mathrm{f}}\right)$ harvested along the eastern shore of Lake St. Clair, Ontario, during the 2014-2015 hunting season and the 2015-2016 hunting season. Important variables are shown in bold.

\begin{tabular}{|c|c|c|c|c|c|c|c|c|}
\hline \multirow[b]{2}{*}{ Variable } & \multicolumn{4}{|c|}{ 2014-2015 Hunting season } & \multicolumn{4}{|c|}{ 2015-2016 Hunting season } \\
\hline & Est. & $85 \% \mathrm{CLs}$ & $95 \% \mathrm{CLs}$ & $\Sigma w$ & Est. & $85 \%$ CLs & $95 \%$ CLs & $\Sigma w$ \\
\hline$\overline{\text { Age }}$ & 1.3 & $(-2,4.6)$ & $(-3.1,5.8)$ & 0.27 & 3.5 & $(1.3,5.6)$ & $(0.5,6.4)$ & 0.84 \\
\hline Day of season & -6.5 & $(-9.7,-3.3)$ & $(-10.9,-2.1)$ & 0.95 & -3.1 & $(-5.2,-0.9)$ & $(-6.0,-0.1)$ & 0.75 \\
\hline Sex & 4.4 & $(1.2,7.6)$ & $(0,8.8)$ & 0.70 & 0.6 & $(-1.6,2.7)$ & $(-2.4,3.5)$ & 0.28 \\
\hline Intercept & -107.6 & $(-110.8,-104.4)$ & $(-112.0,-103.3)$ & - & -114.0 & $(-116.1,-111.8)$ & $(-116.9,-111.0)$ & - \\
\hline
\end{tabular}

Fig. 3. Stable hydrogen isotopes $\left({ }^{2} \mathrm{H} /{ }^{1} \mathrm{H}\right)$ in Mallard (Anas platyrhynchos) wing feathers $\left(\delta^{2} \mathrm{H}_{\mathrm{f}}, n=237\right.$ individuals) harvested along the eastern shore of Lake St. Clair (LSC), Ontario, as a function of origin, sex, age, and day of season. "Local" birds originated at the same latitude as LSC, whereas "Northern" birds originated to the north of LSC. Shown are origins based on 2:1 odds ratio criterion and mean of minimum and maximum estimates of local water $\delta^{2} \mathrm{H}$. Whiskers of box plots represent $1.5 \times$ the interquartile range. Numbers above box plots are sample sizes (number of birds).
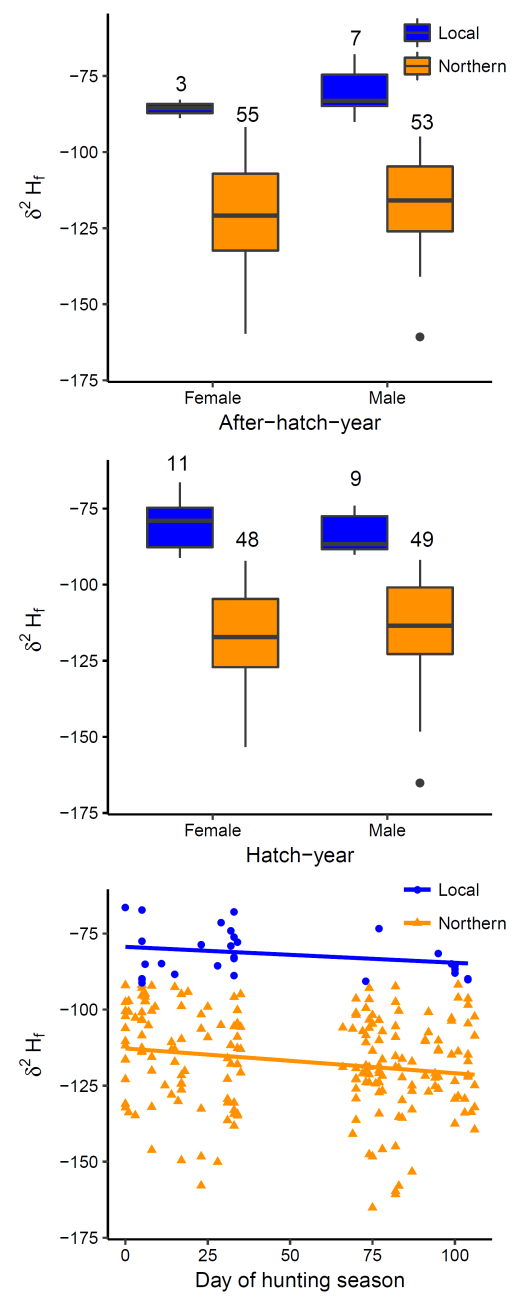

Fig. 4. Depiction of probable origins of immigrant Mallards (Anas platyrhynchos) harvested along the eastern shore of Lake St. Clair, Ontario, 2014-2016. Legend number corresponds to number of individuals assigned at each pixel based on a 2:1 odds ratio criterion (see Methods). (A) Origins without the application of a Bayesian prior spatial mask based on banding data. (B) Depiction constrained to the Mississippi flyway because it was the flyway with by far the highest band recovery probability: Central, 0.017; Mississippi, 0.829; Atlantic, 0.154.

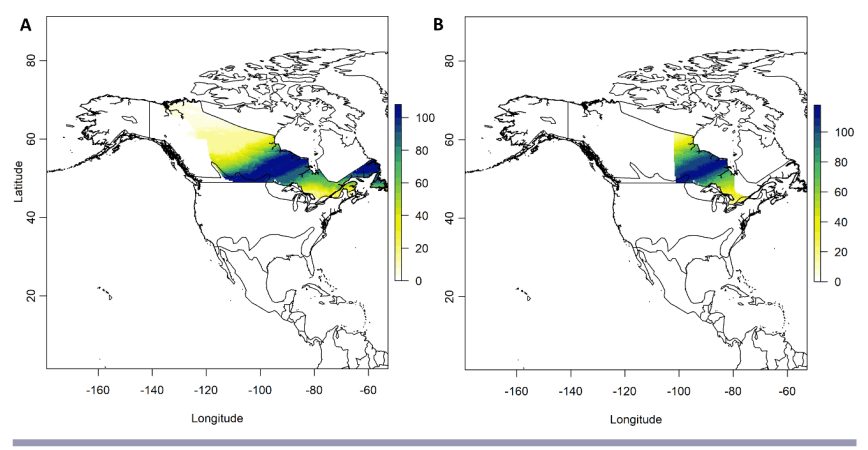

\section{DISCUSSION}

We found that greater than $75 \%$ of HY Mallards and greater than $85 \%$ of AHY Mallards harvested at LSC showed $\delta^{2} \mathrm{H}_{\mathrm{f}}$ values compatible with natal and molting grounds north of the LSC system. This finding is important because harvest management strategies in the Great Lakes states aim to reduce the impact of hunting on local Mallards (Coluccy et al. 2008). Most harvested Mallards in these areas are thought to be produced locally (Anderson and Henry 1972, Munro and Kimball 1982, Zuwerink 2001, Singer 2014), and nonbreeding season survival of adult females is thought to largely influence population growth of Great Lakes Mallards (Coluccy et al. 2008). Our observations, however, suggest that harvest management strategies that try to protect locally breeding AHY females may not be as effective as currently perceived, and perhaps not even required, at least in the context of LSC. Harvested Mallards from the eastern shore of LSC had a much greater probability of originating from the boreal wetlands of northwest Ontario than being from a local population. Whether this pattern is representative of locations in the Great Lakes region beyond our study area is unknown but is of great relevance for harvest management. 
The composition of local versus immigrant Mallards is uncertain for waterfowl harvests throughout the Great Lakes region, although some acknowledge there may be overestimation of locally produced birds (Singer 2014). The Hudson Bay lowlands of northwest Ontario is an expansive wetland region with observed Mallard densities as great as 62 pairs $/ 100 \mathrm{~km}^{2}$, but banding operations are less extensive in this region (Zoltai 1973, Dennis 1974, Singer 2014; Weaver, Petrie, Richman, et al., unpublished manuscript). Our results show that Mallards originating from this undersampled region make up the largest proportion of the Mallards harvested at LSC. Based on this, it is possible that ducks harvested in the Great Lakes states and other parts of Ontario may have similar origins as those that are harvested in LSC, and there is the potential for overestimation of local harvest derivation within these areas. As such, we are expanding our study with plans to examine isotope-based origins of Mallards and other harvested waterfowl species at other major migratory staging areas, as well as intervening breeding areas, throughout the Great Lakes region. With the expanded sampling, we hope to refine our understanding of the origins of hunter-harvested waterfowl throughout larger portions of the Great Lakes region and potentially contribute in a more meaningful way to informing conservation actions for waterfowl than accomplished so far with the present study.

The LSC region and much of the rest of southwestern Ontario has experienced substantial wetland loss (Ducks Unlimited Canada 2010), which has resulted in sparse and minimal Mallard breeding habitat (Messmer et al. 2015). It is tempting to explain the low proportion of locally harvested Mallards in our study as being a direct consequence of wetland loss and low amounts of suitable habitat to support and produce local birds. However, we also observed that more local HY birds were harvested than local adults. Plus, during the 2014-2015 hunting season, we observed differences in $\delta^{2} \mathrm{H}_{\mathrm{f}}$ based on sex, with females originating from more northern latitudes compared with males, suggesting that locally produced females are harvested relatively less than males. These results are expected, given that juvenile Mallards experience greater harvest rates across all breeding stocks of North America (Alisauskas et al. 2014) and hunting is prominent in the LSC region (Palumbo 2017). Additionally, direct recovery rates of Mallards banded on the eastern shore of LSC for the 2014-2015 and 2015-2016 hunting seasons reflect similar differences in vulnerability to harvest based on age, where HY birds had relatively greater direct recovery rates (female $13.89 \%$ [SE $\pm 2.58 \%$ ], male $17.31 \%$ [SE \pm 1.76$]$ ) than adult Mallards (female 10.11\% [SE $\pm 2.27 \%$, male 9.71\% [SE $\pm 1.08 \%$ ]; Palumbo and Shirkey, unpublished data; see also Dufour et al. 1993). So alternatively, our results could be reflective of disproportionally greater abundance of HY Mallards in the population or selective harvest by hunters to target males. Further investigations of age-specific female survival rates and hunter strategies could help to elucidate these potentially confounding factors.

We present yet another strong example of how stable isotope measurements of feathers of harvested waterfowl can be used to inform management and conservation strategies. The key is that the approach does not require initial sampling and so is not biased by effort at origins of banding, although it may be biased in some locations during certain time periods as a function of harvest (e.g., Dufour et al. 1993). On the other hand, our predictive isoscapes and the use of a single measure (i.e., $\delta^{2} \mathrm{H}$ ) can result in ambiguity in assignment. Another key area of consideration is the calibration algorithm linking waterfowl feathers to long-term patterns of $\delta^{2} \mathrm{H}$ in precipitation. We are fortunate to have a waterfowl-specific calibration, but further ground truthing of feather $\delta^{2} \mathrm{H}$ of waterfowl across large latitudinal gradients would continue to be informative (Hobson and Wassenaar 2019). Ideally, isotopic assignment of individual Mallards to origins would use a Mallard-specific derived calibration algorithm associating $\delta^{2} \mathrm{H}$ values in feathers with the most appropriate environmental water surface, e.g., amountweighted precipitation or surface water isoscape (Hobson 2019). In addition, that algorithm would ideally be derived separately for both sexes and each age class and would be based on knownorigin individuals spanning the same geographic range. Such calibration algorithms are not currently available for our species or study population, and we have no way of determining how accurately the scaup calibration we have reported represents our study species. Other studies on passerines have demonstrated small differences in calibration algorithms for $\delta^{2} \mathrm{H}$ based on foraging guild (Hobson et al. 2014), but we are not aware of any similar reports for waterfowl. We are also aware that calibration algorithms can be slightly different for AHY and HY individual passerines (reviewed in Haché et al. 2014), but again, these data are not available for waterfowl. We could not use our own data for a rescaling function because of not having samples from known-origin birds. We are aware of other data sets (Wojtaszek, Tozer, and Hobson, unpublished data) from the region that displayed isotopic similarities among AHY female and HY waterfowl of several species of birds, but not for males, which would be consistent with males undergoing a molt migration. We encourage researchers to establish species- and age-specific algorithms for the waterfowl and other species of interest.

Also, our Bayesian assignment approach propagates known sources of error and in general is conservative based on the odds ratio approach we have used and our estimate of the variance associated with feather $\delta^{2} \mathrm{H}$ at a given geographic location. We encourage authors to experiment with various assignment approaches. We contrasted a 2:1 versus $3: 1$ odds selection at the pixel level and further considered a range of local water $\delta^{2} \mathrm{H}$ values likely driving food webs of molting birds. Our use of Bayesian priors related to the probability of birds being derived from alternate flyways also assisted in further constraining our assignments. Fortunately, in our case, it was relatively straightforward to identify clear local versus immigrant individuals, but this will not always be the case. Regardless, as a result of its unique potential to fill knowledge gaps, we advocate the use of the stable isotope technique in the management of North American waterfowl and encourage more research in this area (Hobson et al. 2009, Asante et al. 2017).

Responses to this article can be read online at: http://www.ace-eco.org/issues/responses.php/1389 


\section{Acknowledgments:}

We thank Kevin Kardynal for his assistance in performing the assignments and for producing the figures depicting origins. The project was financed through a research operating grant from Environment and Climate Change Canada (ECCC) to K. A. Hobson, Bird Studies Canada's Long Point Waterfowl and Wetlands Research Program, Wildlife Habitat Canada, SC Johnson, Canadian Wildlife Service, Ducks Unlimited Canada, Kenneth M. Molson Foundation, Ontario Federation of Anglers and Hunters, TD Friends of the Environment Foundation, California Waterfowl Association, The Bluff's Hunting Club, the sponsors of the "Mallard Tracker" program, and donations from Mr. B. Parfet and Mr. T. Rex. We would like to thank the hunters, guides, and area managers, especially J. Reaume, M. Frak, J. Bradley, and M. Suzor, that allowed us to sample wings from LSC. We would like to thank J. Vanos for assistance with ageing and sexing wings, and the many volunteers and technicians that assisted with collecting wings and entering data, especially B. Cooke, S. Lynch, J. Van Zyl, and R. Ye. We also would like to thank S. Petrie for his considerable contributions to research at LSC. Geoff Koehler and Chantel Gryba assisted with stable isotope analyses at the ECCC lab in Saskatoon. We also greatly appreciate the review and comments provided by the Long Point Waterfowl and Wetlands Research Program Scientific Advisory Committee, the subject editor, and anonymous reviewers.

\section{LITERATURE CITED}

Alisauskas, R. T., T. W. Arnold, J. O. Leafloor, D. L. Otis, and J. S. Sedinger. 2014. Lincoln estimates of Mallard (Anas platyrhynchos) abundance in North America. Ecology and Evolution 4:132-143. https://doi.org/10.1002/ece3.906

Anderson, D. R., and C. J. Henry. 1972. Population ecology of the mallard: I. A review of previous studies and the distribution and migration from breeding areas. Resource Publication 105. U.S. Fish and Wildlife Service, Washington, D.C., USA.

Arnold, T. W. 2010. Uninformative parameters and model selection using Akaike's information criterion. Journal of Wildlife Management 74:1175-1178. https://doi.org/10.1111/j.1937-2817.2010. tb01236.x

Asante, C. K., T. D. Jardine, S. L. Van Wilgenburg, and K. A. Hobson. 2017. Tracing origins of waterfowl using the Saskatchewan River Delta: incorporating stable isotope approaches in continent-wide waterfowl management and conservation. Condor: Ornithological Applications 119:261-274. https://doi.org/10.1650/CONDOR-16-179.1

Ashley, P., K. A. Hobson, S. L. Van Wilgenburg, N. North, and S. A. Petrie. 2010. Linking Canadian harvested juvenile American black ducks to their natal areas using stable isotope $\left(\delta \mathrm{D}, \delta^{13} \mathrm{C}\right.$, $\left.\delta^{15} \mathrm{~N}\right)$ methods. Avian Conservation and Ecology 5(2):7. https:// doi.org/10.5751/ACE-00397-050207

Austin, J. E., A. D. Afton, M. G. Anderson, R. G. Clark, C. M. Custer, J. S. Lawrence. J. B. Pollard, and J. K. Ringleman. 2000. Declining scaup populations: issues, hypotheses, and research needs. Wildlife Society Bulletin 28:254-263.
Baldassarre, G. A. 2014. Ducks, geese, and swans of North America. Volume 1. John Hopkins University Press, Baltimore, Maryland, USA.

Baldassarre, G. A., and E. G. Bolen. 2006. Waterfowl ecology and management. Second edition. Krieger, Malabar, Florida, USA.

Bookhout, T. A., K. D. Bednarik, and R. W. Kroll. 1989. The Great Lakes marshes. Pages 131-156 in L. M. Smith, R. L. Pedersson, and R. M. Kaminski, editors. Habitat management for wintering and migrating waterfowl in North America. Texas Tech University Press, Lubbock, Texas, USA.

Bowen, G. J., and J. Revenaugh. 2003. Interpolating the isotopic composition of modern meteoric precipitation. Water Resources Research 39:1299. https://doi.org/10.1029/2003WR002086

Bowen, G. J., L. I. Wassenaar, and K. A. Hobson. 2005. Global application of stable hydrogen and oxygen isotopes to wildlife forensics. Oecologia 143:337-348. https://doi.org/10.1007/ s00442-004-1813-y

Burnham, K. P., and D. R. Anderson. 2002. Model selection and multimodel inference: a practical information-theoretic approach. Springer-Verlag, New York, New York, USA.

Caizergues, A., S. L. Van Wilgenburg, and K. A. Hobson. 2016. Unraveling migratory connectivity of two European diving ducks: a stable isotope approach. European Journal of Wildlife Research 62:701-711. https://doi.org/10.1007/s10344-016-1048-3

Carney, S. M. 1992. Species, age and sex identification of ducks using wing plumage. U.S. Department of the Interior, U.S. Fish and Wildlife Service, Washington, D.C., USA.

Chabot, A. A., K. A. Hobson, S. L. Van Wilgenburg, G. J. McQuat, and S. C. Lougheed. 2012. Advances in linking wintering migrant birds to their breeding-ground origins using combined analyses of genetic and stable isotope markers. PLOS ONE 7: e43627. https://doi.org/10.1371/journal.pone.0043627

Clark, R. G., K. A. Hobson, and L. I. Wassenaar. 2006. Geographic variation in isotopic $\left(\delta \mathrm{D}, \quad \delta^{13} \mathrm{C}, \quad \delta^{15} \mathrm{~N}, \quad \delta^{34} \mathrm{~S}\right)$ composition of feathers and claws from lesser scaup and northern pintail: implications for studies of migratory connectivity. Canadian Journal of Zoology 84:1395-1401. https://doi. org/10.1139/z06-135

Clark, R. G., K. A. Hobson, and L. I. Wassenaar. 2009. Corrigendum - geographic variation in the isotopic $\left(\delta \mathrm{D}, \delta^{13} \mathrm{C}\right.$, $\delta^{15} \mathrm{~N}, \delta^{34} \mathrm{~S}$ ) composition of feathers and claws from lesser scaup and northern pintail: implications for studies of migratory connectivity. Canadian Journal of Zoology 87:553-554. https:// doi.org/10.1139/Z09-059

Coluccy, J. M., T. Yerkes, R. Simpson, J. W. Simpson, L. Armstrong, and J. Davis. 2008. Population dynamics of breeding Mallards in the Great Lakes states. Journal of Wildlife Management 72:1181-1187. https://doi.org/10.2193/2007-039

Dennis, D. G. 1974. Breeding pair surveys of waterfowl in southern Ontario. Pages 45-52 in H. Boyd, editor. Canadian Wildlife Service waterfowl studies in eastern Canada 1969-1973. Canadian Wildlife Service Report Series No. 29. Information Canada, Ottawa, Ontario, Canada 
Dennis, D. G., G. B. McCullough, N. R. North, and R. K. Ross. 1984. An updated assessment of migrant waterfowl use of Ontario shorelines of the southern Great Lakes. Pages 37-42 in S. G. Curtis, D. G. Dennis, and H. Boyd, editors. Waterfowl studies in Ontario, 1973-81. Canadian Wildlife Service Occasional Paper No. 54. Canadian Wildlife Service, Ottawa, Ontario, Canada.

Ducks Unlimited Canada. 2010. Southern Ontario wetland conversion analysis. Ducks Unlimited Canada, Stonewall, Manitoba, Canada.

Dufour, K. W., C. D. Ankney, and P. J. Weatherhead. 1993. Condition and vulnerability to hunting among Mallards staging at Lake St. Clair, Ontario. Journal of Wildlife Management 57:209-215. https://doi.org/10.2307/3809415

Haché, S., K. A. Hobson, E. M. Bayne, S. L. Van Wilgenburg, and M. A. Villard. 2014. Tracking natal dispersal in a coastal population of a migratory songbird using feather stable isotope $\left(\delta^{2} \mathrm{H}, \quad \delta^{34} \mathrm{~S}\right)$ tracers. PLoS ONE 9(4):e94437. https://doi. org/10.1371/journal.pone.0094437

Hobson, K. A. 1999. Tracing origins and migration of wildlife using stable isotopes: a review. Oecologia 120:314-326. https://doi. org/10.1007/s004420050865

Hobson K. A. 2008. Applying isotopic methods to tracking animal movements. Pages 45-78 in K. A. Hobson and L. I. Wassenaar, editors. Tracking animal migration with stable isotopes. Volume 2, Terrestrial ecology. Elsevier, New York, New York, USA. https://doi.org/10.1016/S1936-7961(07)00003-6

Hobson, K. A. 2019. Application of isotopic methods to tracking animal movements. Pages 85-115 in K. A. Hobson and L. I. Wassenaar, editors. Tracking animal migration with stable isotopes. Second Edition. Academic Press, London, UK. https:// doi.org/10.1016/B978-0-12-814723-8.00004-0

Hobson, K. A., S. L. Van Wilgenburg, J. Faaborg, J. D. Toms, C. Rengifo, A. Llanes Sosa, Y. Aubry, and R. Brito Aguilar. 2014. Connecting breeding and wintering grounds of Neotropical migrant songbirds using stable hydrogen isotopes: a call for an isotopic atlas of migratory connectivity. Journal of Field Ornithology 85:237-257. https://doi.org/10.1111/jofo.12065

Hobson, K. A., and L. I. Wassenaar, editors. 2019. Tracking animal migration with stable isotopes. Second edition. Academic, London, UK.

Hobson, K. A., M. B. Wunder, S. L. Van Wilgenburg, R. G. Clark, and L. I. Wassenaar. 2009. A method for investigating population declines of migratory birds using stable isotopes: origins of harvested lesser scaup in North America. PLoS ONE 4:e7915. https://doi.org/10.1371/journal.pone.0007915

Hoekman, S. T., T. S. Gabor, R. Maher, H. R. Murkin, and L. M. Armstrong. 2004. Factors affecting survival of Mallard ducklings in southern Ontario. Condor: Ornithological Applications 106:485-495. https://doi.org/10.1650/7408

Hoekman, S. T., T. S. Gabor, R. Maher, H. R. Murkin, and M. S. Lindberg. 2006a. Deomographics of breeding female mallards in southern Ontario, Canada. Journal of Wildlife Management 70:111-120. https://doi.org/10.2193/0022-541X(2006)70[111:DOBFMI] 2.0. $\mathrm{CO} ; 2$
Hoekman, S. T., T. S. Gabor, M. J. Petrie, R. Maher, H. R. Murkin, and M. S. Lindberg. 2006b. Population dynamics of mallards breeding in agricultural environments in eastern Canada. Journal of Wildlife Management 70:121-128. https://doi.org/10.2193/0022-541X (2006)70[121:PDOMBI]2.0.CO;2

Messmer, D. J., S. A. Petrie, S. S. Badzinski, M. L. Gloutney, and M. L. Schummer. 2015. Habitat associations of breeding mallards and Canada geese in southern Ontario, Canada. Wildlife Society Bulletin 39:543-552. https://doi.org/10.1002/wsb.550

Munro, R. E., and C. F. Kimball. 1982. Population ecology of the Mallard. VII. Distribution and derivation of the harvest. U.S. Fish and Wildlife Service Resource Publication 147. U.S. Fish and Wildlife Service, Laurel, Maryland, USA.

Nichols, J. D., F. A. Johnson, and B. K. Williams. 1995. Managing North American waterfowl in the face of uncertainty. Annual Review of Ecology and Systematics 26:177-199. https://doi. org/10.1146/annurev.es.26.110195.001141

Norris, D. R., and C. M. Taylor. 2006. Predicting the consequences of carry-over effects for migratory populations. Biology Letters 2:148-151. https://doi.org/10.1098/rsb1.2005.0397

Palumbo, M. 2017. Resource selection, survival, and departure of adult female mallards from the Lake St. Clair region during autumn and winter. Dissertation, Western University, London, Ontario, Canada.

R Core Team. 2018. R: a language and environment for statistical computing. R Foundation for Statistical Computing, Vienna, Austria. [online] URL: https://www.R-project.org/

Ridgely, R. S., T. F. Allnutt, T. Brooks, D. K. McNicol, D. W. Mehlman, B. E. Young, and J. R. Zook. 2007. Digital distribution maps of the birds of the Western Hemisphere, version 3.0. NatureServe, Arlington, Virginia, USA.

Sauer, J. R., G. S. Zimmerman, J. D. Klimstra, and W. A. Link. 2014. Hierarchical model analysis of the Atlantic Flyway Breeding Waterfowl Survey. Journal of Wildlife Management 78:1050-1059 https://doi.org/10.1002/jwmg.748

Singer, H. 2014. Factors affecting productivity and harvest rates of Great Lakes mallards. Thesis. Michigan State University, East Lansing, Michigan, USA.

Studds, C. E., and P. P. Marra. 2005. Nonbreeding habitat occupancy and population processes: an upgrade experiment with a migratory bird. Ecology 86:2380-2385. https://doi.org/10.1890/04-1145

Szymanski, M. L., A. D. Afton, and K. A. Hobson. 2007. Use of stable isotope methodology to determine natal origins of mallards at a fine scale within the upper Midwest. Journal of Wildlife Management 71:1317-1324. https://doi.org/10.2193/2006-188

Theodory, R. G. 1999. The distribution of stable isotopes and heavy metals in Dreissena polymorpha (zebra mussel): chemical tracers for environmental contamination in Lake St. Clair (Ontario, Michigan). Dissertation, University of Windsor, Windsor, Ontario, Canada.

U.S. Fish and Wildlife Service. 2017. Adaptive harvest management: 2018 hunting season. U.S. Department of Interior, Washington, D.C., USA. 
U.S. Geological Survey. 2017. Gamebirds. U.S. Geological Survey, Patuxent, Maryland, USA.

Van Wilgenburg, S. L., and K. A. Hobson. 2011. Combining stable isotope $(\delta \mathrm{D})$ and band recovery data to improve probabilistic assignment of migratory birds to origin. Ecological Applications 21:1340-1351. https://doi.org/10.1890/09-2047.1

Van Wilgenburg, S. L., K. A. Hobson, K. R. Brewster, and J. M. Welker. 2012. Assessing dispersal in threatened migratory birds using stable hydrogen isotope $(\delta \mathrm{D})$ analysis of feathers. Endangered Species Research 16:17-29. https://doi.org/10.3354/ esr00383

Wassenaar, L. I., and K. A. Hobson. 2003. Comparative equilibration and online technique for determination of nonexchangeable hydrogen of keratins for use in animal migration studies. Isotopes in Environmental and Health Studies 39:211-217. https://doi.org/10.1080/1025601031000096781

Williams, B. K., and F. A. Johnson. 1995. Adaptive management and the regulation of waterfowl harvests. Wildlife Society Bulletin 23:430-436.

Wunder, M. B. 2010. Using isoscapes to model probability surfaces for determining geographic origins. Pages 251-270 in J. B. West, G. J. Bowen, T. E. Dawson, K. P. Tu, editors. Isoscapes: understanding movement, pattern, and process on Earth through isotope mapping. Springer, Dordrecht, The Netherlands. https:// doi.org/10.1007/978-90-481-3354-3_12

Wunder, M. B. 2012. Determining geographic patterns of migration and dispersal using stable isotopes in keratins. Journal of Mammalogy 93:360-367. https://doi.org/10.1644/11-MAMMS-182.1

Yerkes, T., K. A. Hobson, L. I. Wassenaar, R. Macleod, and J. M. Coluccy. 2008. Stable isotopes $\left(\delta \mathrm{D}, \delta^{13} \mathrm{C}, \delta^{15} \mathrm{~N}\right)$ reveal associations among geographic location and condition of Alaskan northern pintails. Journal of Wildlife Management 72:715-725. https://doi.org/10.2193/2007-115

Zoltai, S. C. 1973. Vegetation, surficial deposits and permafrost relationships in the Hudson Bay lowland. Pages 17-34 in Proceedings of the symposium on the physical environment of the Hudson Bay lowland (Guelph 1973). Department of Land Resource Science, University of Guelph, Guelph, Ontario, Canada.

Zuwerink, D. A. 2001. Changes in the derivation of Mallard harvests from the northern US and Canada, 1966-1998. Dissertation. The Ohio State University, Columbus, Ohio, USA. 
APPENDIX 1. The location of all mallard band recoveries along the eastern shore of Lake St. Clair that were used to determine the probability of flyway origin.

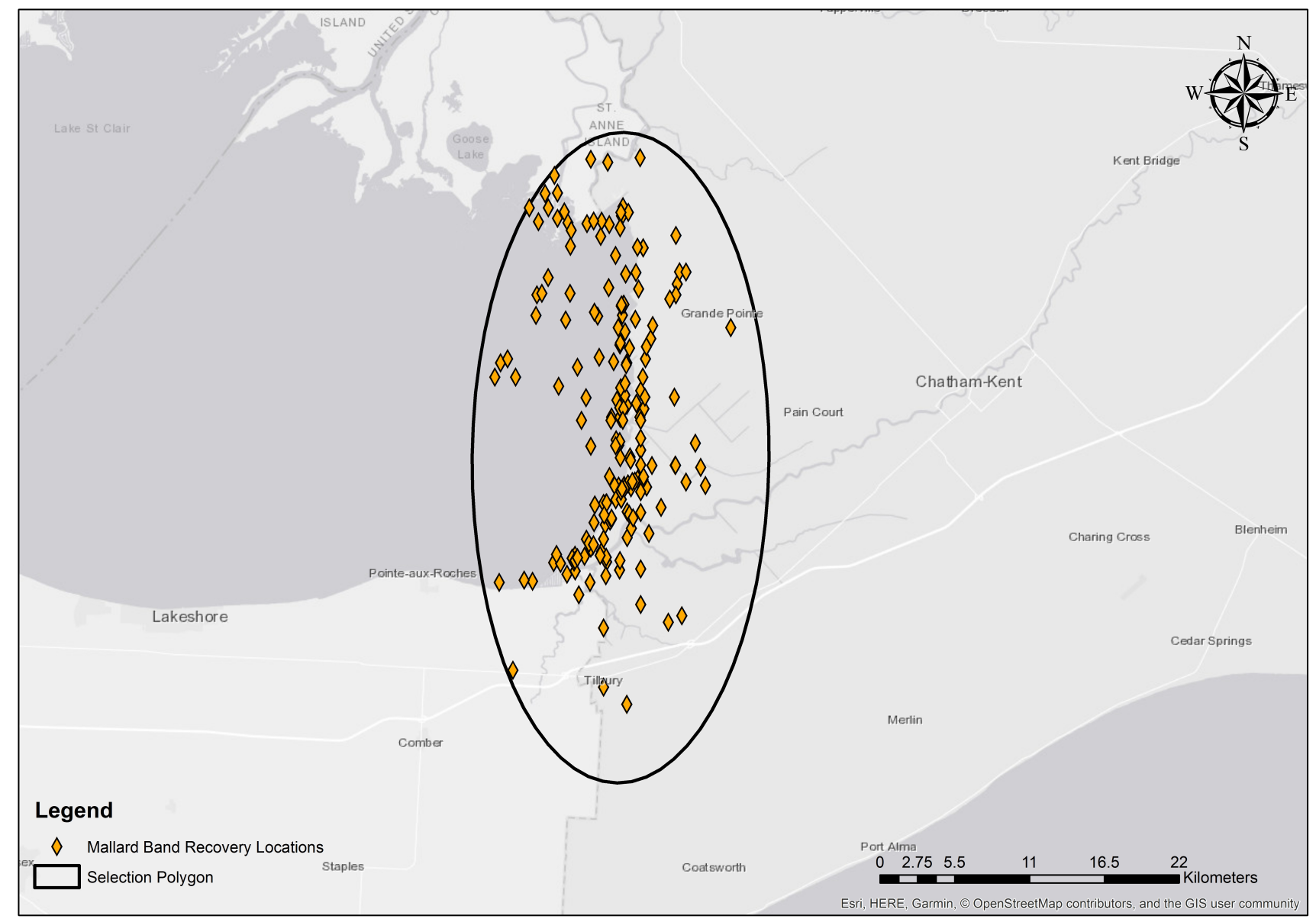


Avian Conservation and Ecology 14(2): 3

http://www.ace-eco.org/vol14/iss2/art3/

Appendix 2. Feather sample data

Please click here to download file 'appendix2.xlsx'. 